\title{
User-fee bill passes US Senate, but legislative hurdles remain
}

After squelching a move to mandate drug imports, the US Senate settled down in May and passed its version of a bill to renew the Prescription Drug User Fee Act, called PDUFA IV. Renewal efforts face major uncertainty in the House of Representatives, however. House members have not drafted a bill to reauthorize PDUFA, which collects fees from companies in part to assure that the US Food and Drug Administration (FDA) has the expertise to meet performance goals for conducting timely product reviews. The current authorization expires in September and, somewhat ominously, leading Democrats in the House pointedly asked FDA officials just how long such legislation could be delayed before "personnel disruptions"- staff cutbacks as PDUFA lapses-would begin to affect drug reviews. If such political brinksmanship prevails, PDUFA IV negotiating could continue late into June and beyond.

Judging from a mid-April hearing convened by the House Committee on Energy and Commerce Subcommittee on Health, lawmakers can find plenty to negotiate. The Senate bill calls for a boost in user fees, embodies major changes in terms of drug safety-particularly for "post-marketing" surveillance and analysis of the safety of licensed products - and includes other provisions to curb potential conflicts of interest, encourage clinical trials involving pediatric patients and provide for voluntary reviews of direct-to-consumer television advertising, among other things. But many of these provisions appear up for grabs as influential House members tune into demands voiced by PDUFA critics or come forward with their own reforms. (It is common practice for legislators to use PDUFA reauthorization as an opportunity to tack on other FDA mandates in addition to user fees. The last renewal, for example, in 2002, included new rules on monitoring advertising and promotion. Before that, in 1997, PDUFA was the vehicle by which the FDA Modernization Act was introduced.)

One major uncertainty is whether Representative Henry Waxman, a Democrat from California, will seek to use PDUFA IV as a vehicle for debating the virtues of follow-on biologics, a potential quagmire issue that Senators sidestepped. Similarly, Democrat Edward Markey of Massachusetts appears poised to decorate PDUFA IV with provisions requiring companies to disclose

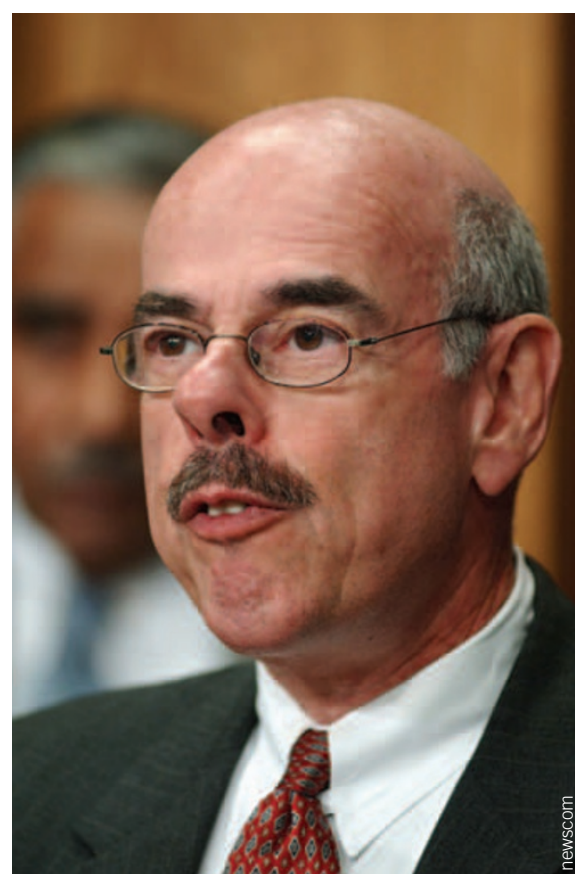

In its bill reauthorizing FDA user fees, the US Senate sidestepped the thorny question of followon biologics. However, Representative Henry Waxman, shown here, may yet raise the issue as the House formulates its version of the legislation.

all of their clinical trial data. Any effort to deal with these or similarly controversial issues would greatly complicate efforts to reauthorize this legislation, whose approaching deadline makes it a tempting means for forcing just such debates.

Short of such hotly contested measures, the basic underpinnings of PDUFA IV currently seem beleaguered in the House. After negotiations with representatives from the biotech and pharmaceutical industries as well as other stakeholders, FDA officials are recommending that user fees be increased by $\$ 87.4$ million per year to an estimated total of $\sim \$ 438$ million in user fees for fiscal year (FY) 2008, according to Theresa Mullin, FDA assistant commissioner for planning.

Escalating user fees are a thorn, even for the bill's proponents. "BIO [the Washingtonbased Biotechnology Industry Organization] is concerned that FDA's overreliance on industry fees creates an unseemly misperception that FDA is beholden to the industry it regulates," says Kay Holcombe, a senior policy advisor for Cambridge, Massachusetts-based Genzyme, who presented testimony for BIO at the House subcommittee hearing in April. Although increased user fees are needed, she adds, "FDA also needs increased appropriations to continue its mission."

Meanwhile, some groups are actively lobbying against escalating those user fees, while others urge that they be abolished. For example, several dozen academics and former FDA officials belonging to the Project on Scientific Knowledge and Public Policy, called SKAPP, are adamant, urging Congress not to reauthorize FDA user fees but to fund the agency solely with "increased direct appropriations." SKAPP argues that reliance on user fees stands in the way of FDA's fundamental mission "to protect and advance the public's health." PDUFA reauthorization is therefore warranted only if absolutely vital to keep FDA running and then for a single year, followed by a comprehensive reevaluation, reasons the group's director, Susan Wood, from George Washington University in Washington, DC. Wood was director of the FDA Office of Women's Health, but resigned in 2005 over delays in approving Plan B emergency contraceptives for overthe-counter sales (Nat. Biotechnol. 25, 495, 2007).

"Over half the FDA drug budget is funded by the industry it regulates," adds William Vaughan, a senior policy analyst for Consumers Union of Yonkers, New York. "If there were ever a public function that should be funded out of the Treasury, this is it." $\mathrm{He}$ cites several recent surveys indicating that substantial majorities in the general population are concerned that so much of FDA funding comes from industry.

Ultimately, however, Vaughan accepts user fees and recommends that a greater proportion of these resources be used to enable FDA to conduct postmarketing drug safety programs. Like Vaughan, William Hubbard from the Coalition for a Stronger FDA urges spending more of user fees to support postmarketing safety reviews. Hubbard also recommends increasing spending by $\$ 40$ million per year to support the FDA Critical Path Initiative, which has languished due to a lack of funding and dedicated personnel.

Jeffrey L. Fox, Washington

For more news and analysis go to news@nature.com www.nature.com/news 